\title{
Tuberculin response two years after BCG vaccination at birth
}

\author{
H GRINDULIS, M I D BAYNHAM, P H SCOTT, R A THOMPSON, AND B A WHARTON
}

Sorrento Maternity Hospital and the Regional Immunology Laboratory, East Birmingham Hospital, Birmingham

SUMmaRY One hundred and forty nine Asian children who received BCG vaccine shortly after birth were reviewed at the age of 22 months. Many of them had an apparently inadequate response to the vaccine. A quarter had no scar, and half of the children with a scar had a negative response to $10 \mathrm{TU}$ (Mantoux 1/1000) and these children showed only limited lymphocyte transformation in vitro in response to tuberculin. Various measurements of health at age 22 months suggested the Mantoux negative children were less privileged than the Mantoux positive ones, but the differences were not striking and most were not significant. It seemed more likely that the high incidence of poor response was due to some factor operating in the perinatal period. There was circumstantial evidence implicating perinatal nutrition, and there is a theoretical possibility of interference with vaccination by maternal antibody.

BCG vaccination shortly after birth has been shown to protect against tuberculosis in Canadian Indians $(80 \%)^{1}$ and in Chicago $(75 \%)^{2}$ The policy in Birmingham for some years has been to offer BCG vaccination to all Asian babies at birth, and this policy has been recently endorsed. ${ }^{3}$ Nevertheless, the efficacy of BCG vaccination has been questioned. Studies in older children and adults showed $77 \%$ protection in Britain, ${ }^{4}$ only $14 \%$ in southern USA,${ }^{5}$ and virtually none in Madras. ${ }^{6}$ Ten Dam et $a l,{ }^{7}$ while commending BCG vaccination, suggested that the protection obtained when this was given at birth required further evaluation. As part of an assessment of the health of Asian toddlers we had the opportunity to check tuberculin sensitivity and other aspects of cell mediated immunity in children who received BCG at birth.

\section{Methods}

Patients. The children studied were all born at Sorrento Maternity Hospital between September 1979 and October 1980. Their mothers had taken part in a controlled trial of protein energy supplementation in pregnancy whereby some received a protein energy vitamin supplement, some an energy vitamin supplement, and others (controls) a vitamin supplement only. ${ }^{89}$ Therefore, detailed anthropometric, clinical, and biochemical data were avail- able for the pregnancy and early neonatal period. The social circumstances of the mothers and their families had been determined during the pregnancy as follows (mean (SD)): maternal age $24.3(5)$ years; number of siblings $1.3(1.7)$; number of years in England 5.4 (5.5); occupants per room $1 \cdot 3(0 \cdot 6)$; father's social class $3.5(0.8)$ (according to Registrar General's classification); mother's educational class $2.3(1.7)$ (grade $0=$ no education; grade $1=1$ to 5 years' primary education; grade $2=6$ to 11 years secondary education; grades 3 to $6=6$ th form, vocational and foreign college/university education; grade $7=$ British university degree); mother's language ability $2.4(1.3) \quad(1=$ no English, $2=$ single words, $4=$ fluent).

The group included 57\% Moslems (from Pakistan and Bangladesh), $19 \%$ Hindus (mainly from Gujurat), and $24 \%$ Sikhs (from Indian Punjab). A total of 149 children were seen at 21 to 23 months of age at their local child health clinic. A health visitor from each of the four clinics and an interpreter helped with the assessment of the children.

\section{Phase I-preliminary screening of tuberculin sensi-} tivity

The general health of the 149 children was assessed by the following means:

(a) Anthropometry (weight in napkin and vest, supine length on stadiometer, triceps and subscapu- 
lar skinfold thickness using Harpenden calipers, head circumference). Measurements of height and weight were expressed as SD score of the National Centre for Health Statistics standards. ${ }^{10}$

(b) Clinical examination.

(c) Developmental score in months using selected criteria from the Denver developmental screening chart.

(d) Haematological and biochemical assessment including full blood count, haemoglobin electrophoresis, serum zinc, iron, transferrin, albumin, alkaline phosphatase, alkaline ribonuclease and vitamin $\mathrm{D}$-all measured by conventional methods.

A history of recent illness was excluded on questioning. During examination a BCG scar was noted to be present in 112 children; 37 had no scar despite having received BCG at birth. Tuberculin testing was performed with $10 \mathrm{U}$ purified protein derivative intradermally $(0 \cdot 1 \mathrm{ml} 1 / 1000$ Mantoux reagent). This was administered by one of us (HG) and the amount of induration was measured 48 hours later by the health visitors. Sample readings by each health visitor were checked by $\mathrm{HG}$ to ensure uniformity. A positive result was regarded as an induration of $5 \mathrm{~mm}$ diameter or greater when read in a transverse direction across the forearm. ${ }^{11}$

\section{Phase II-further evaluation of Mantoux negative} children

Forty children from phase I who had a negative response to $10 \mathrm{U}$ purified protein derivative were seen again and given $100 \mathrm{U}(0 \cdot 1 \mathrm{ml} 1 / 100)$ purified protein derivative intradermally in the opposite forearm. The result was read at their homes 48 hours later by HG. Other tests of cell mediated immunity which were performed in most of the children were in vitro lymphocyte transformation responses to phytohaemagglutinin, pokeweed mitogen, and tuberculin.

Lymphocyte transformation was measured by separating lymphocytes from heparinised blood on a Ficoll density gradient. ${ }^{12}$ After washing in RPMI they were dispersed into wells in a microlitre tray at a concentration of $10^{5}$ lymphocytes in $0 \cdot 1 \mathrm{ml}$ RPMI 1640 (tissue culture medium produced by Roswell Park Memorial Institute) plus $10 \%$ human $\mathrm{AB}$ serum. A similar volume of buffer alone, or buffer containing various concentrations of phytohaemagglutinin $(50,25,5 \mu \mathrm{g} / \mathrm{ml})$, pokeweed mitogen $(50$, $25,5 \mu \mathrm{g} / \mathrm{ml})$, or tuberculin $(250,50,5 \mu \mathrm{g} / \mathrm{ml})$ were added in triplicate to different wells. After two days in culture for phytohaemagglutinin and 6 days for pokeweed mitogen and tuberculin, $\mathrm{H}^{3}$-thymidine was added to the plates and the cells were then harvested 18 hours later. After precipitation of the protein with trichloroacetic acid the residue was taken up into scintillation fluid and counted in a scintillation counter. Results were obtained as disintegrations per minute (dpm) of the mean of the test cultures minus the mean of unstimulated cultures and expressed as dpm $/ 10^{5}$ lymphocytes.

A blood sample was taken at the same clinic from a healthy adult European control (usually HG), and the lymphocytes cultured in an identical manner. In the analysis of results the ratio of the dpm obtained in the patient's cultures to that of the cultures of control lymphocytes was used.

\section{Results}

BCG scar and Mantoux reaction. A quarter of the children given BCG at birth had no visible scar (Fig. 1). Of children with a scar about a half had a negative response to $10 \mathrm{TU}$ (Mantoux 1/1000) and a fifth of these (that is, about a tenth of children with a scar) were also negative to $100 \mathrm{TU}$ (Mantoux 1/100).

In many of the results that follow comparisons are made of what, for simplicity, we have called the three 'Mantoux groups', that is scar absent $(n=37)$; scar present, positive reaction to Mantoux $1 / 1000$ $(\mathrm{n}=58)$; scar present, negative reaction to Mantoux $1 / 1000(n=54)$.

Other tests of cell mediated immunity. Fig. 2 shows lymphocyte transformation after stimulation with non-specific mitogens (phytohaemaglutinin; pokeweed mitogen) and purified protein derivative anti-

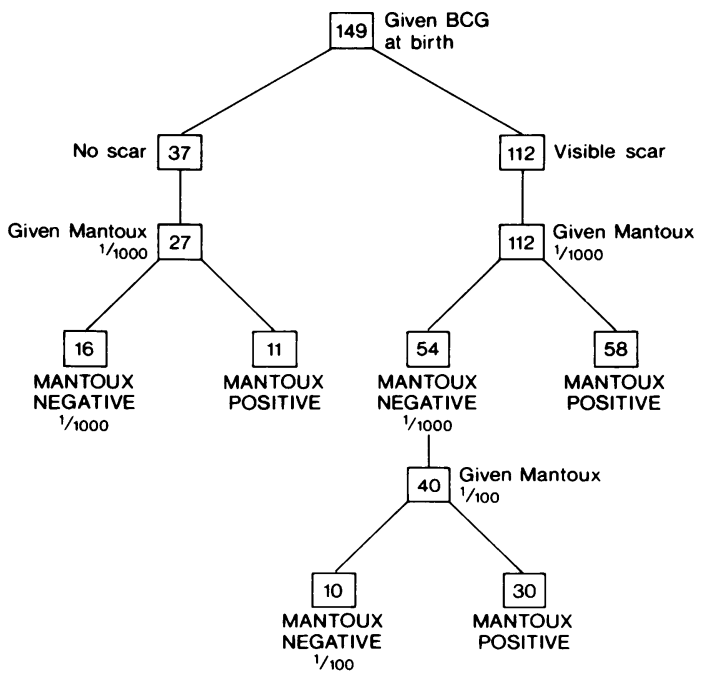

Fig. 1 Tuberculin response in 149 Asian children age 22 months who were given $B C G$ at birth. 


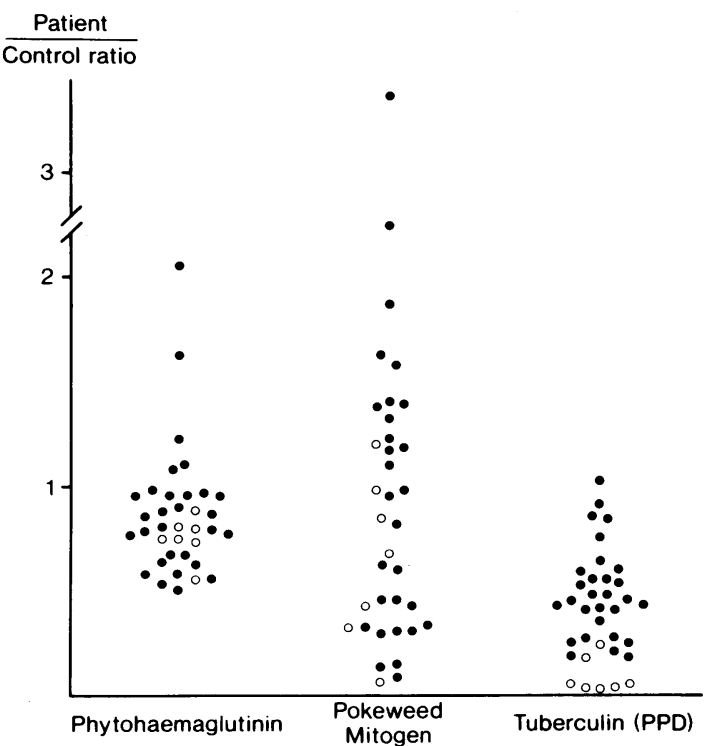

Fig. 2 Lymphocyte transformation in response to $50 \mu \mathrm{g} / \mathrm{ml}$ mitogen or antigen in Mantoux $1 / 1000$ negative children (that is, phase II patients).

Patient: control ratio $\frac{\mathrm{dpm} / 10^{5} \text { patient's lymphocytes }}{\mathrm{dpm} / 10^{5} \text { control lymphocytes }}$

Closed circles, children with $>10000 \mathrm{dpm} / 10^{5}$ lymphocytes response to purified protein derivative.

Open circles, children with $<10000 \mathrm{dpm} / 10^{5}$ lymphocytes response to purified protein derivative.

gen in 32 phase II children (that is, who were negative to Mantoux 1/1000). The response by the patients' lymphocytes to the non-specific mitogens was similar to that in controls, but the reaction to purified protein derivative was substantially less than in the controls. Seven patients had a particularly low response to purified protein derivative in that the patient:control ratio was less than 0.25 and their absolute response was less than $10000 \mathrm{dpm} / 10^{5}$ lymphocytes. In these 7 patients the response to phytohaemagglutin and pokeweed mitogen was a little lower than that of controls.

Inspection of the results showed no clear relation between tuberculin skin sensitivity and in vitro response to purified protein derivative. Of the 7 patients described above with a particularly low in vitro response, only one child had a negative reaction to $100 \mathrm{TU}$ (Mantoux 1/100).

Other aspects of health at 22 months in three Mantoux groups. Compared with Mantoux positive children, Mantoux negative ones were a little behind in gross motor and fine motor development $(\mathrm{P}<0.05)($ Table 1). This deficit was also present in the scar absent group but differences were not significant. The haemoglobin concentration was a little lower (NS) in the Mantoux negative group. When the data were analysed again excluding children with a haemoglobin concentration less than $10 \mathrm{gm} / \mathrm{dl}$, the significant differences in motor development remained and the delay in social development of the Mantoux negative group also became significant $(\mathrm{P}<0 \cdot 05)$.

Compared with the Mantoux positive group, the scar absent children had a smaller head circumference and a higher plasma transferrin concentration. Other measures of iron status were also a little higher but not significantly so.

Other results, not shown in Table 1, indicated that the Mantoux negative children were a little lighter, shorter, and thinner than the Mantoux positive group, they also had a slightly lower plasma albumin concentration and higher plasma ribonuclease activity, but none of the differences approached statistical significance. (Mantoux negative and Mantoux positive groups respectively: weight SD score $0 \cdot 11,0 \cdot 27$; length SD score $0 \cdot 17$, $0 \cdot 22$; weight for height $\mathrm{SD}$ score $0 \cdot 14,0 \cdot 31$; plasma albumin $41 \cdot 6,43 \cdot 4 \mathrm{~g} / \mathrm{l}$; plasma ribonuclease 536 , $508 \mu / 1)$.

The following results were similar in all groups: mean corpuscular haemoglobin, mean corpuscular volume, plasma zinc, plasma vitamin $\mathrm{D}$, length of time breast fed, age at which cows' milk and solids were introduced.

Table 1 Aspects of health in 149 Asian children given $B C G$ vaccination at birth and grouped according to vaccine response at 22 months of age

\begin{tabular}{|c|c|c|c|}
\hline \multirow{2}{*}{$\begin{array}{l}\text { Measurement } \\
\text { Mean (SD) }\end{array}$} & \multicolumn{2}{|c|}{$B C G$ scar present } & \multirow{2}{*}{$\begin{array}{l}\text { BCG scar } \\
\text { absent }\end{array}$} \\
\hline & $\begin{array}{l}\text { Mantoux } \\
1 / 1000 \\
\text { Positive }\end{array}$ & $\begin{array}{l}\text { Mantoux } \\
\text { I/1000 } \\
\text { Negative }\end{array}$ & \\
\hline \multicolumn{4}{|l|}{ Anthropometry* } \\
\hline Head circumference $(\mathrm{cm})$ & $48 \cdot 3(1 \cdot 1)$ & $48 \cdot 1(1 \cdot 3)$ & $47 \cdot 4(1 \cdot 7) \dagger$ \\
\hline \multicolumn{4}{|c|}{ Psychomotor development (mths) } \\
\hline Gross motor & $21.4(1 \cdot 3)$ & $21 \cdot 0(1 \cdot 0) \dagger$ & $21 \cdot 0(1 \cdot 3)$ \\
\hline Fine motor & $21.4(1.6)$ & $20.8(1.4) \dagger$ & $20 \cdot 8(1.7)$ \\
\hline Social & $21 \cdot 2(1 \cdot 5)$ & $20 \cdot 8(1 \cdot 3)$ & $20.9(1.7)$ \\
\hline Language & $21 \cdot 3(1.4)$ & $21 \cdot 0(1.4)$ & $20.7(1.9)$ \\
\hline \multicolumn{4}{|l|}{ Haematology } \\
\hline Haemoglobin (g/dl) & $11 \cdot 3(1 \cdot 5)$ & $11 \cdot 0(1.4)$ & $11.4(1 \cdot 7)$ \\
\hline Serum iron $(\mu \mathrm{mol} / \mathrm{l})$ & $13.9(5 \cdot 7)$ & $14.9(6 \cdot 7)$ & $16.4(8 \cdot 0)$ \\
\hline Serum transferrin $(\mathrm{g} / \mathrm{l})$ & $3.9(1 \cdot 1)$ & $4 \cdot 1(0 \cdot 8)$ & $4 \cdot 2(1 \cdot 6) \dagger$ \\
\hline Transferrin saturation (\%) & $14 \cdot 7(7 \cdot 7)$ & $15 \cdot 1(9 \cdot 9)$ & $16 \cdot 1(9 \cdot 0)$ \\
\hline
\end{tabular}

*Mantoux negative children were a little lighter, shorter, and thinner, than Mantoux positive but this was not significant.

$\nmid$ Result significantly different from that in Mantoux positive group $(\mathrm{P}<0 \cdot 05)$ 
Social and subethnic status of the children. The social and ethnic characteristics of the Mantoux positive and negative groups were broadly similar but different from the scar absent group (Table 2).

Table 2 Social and ethnic characteristics of 149 Asian children given $B C G$ vaccination at birth and grouped according to vaccine response at 22 months of age

\begin{tabular}{|c|c|c|c|}
\hline \multirow[t]{2}{*}{ Characteristic } & \multicolumn{2}{|c|}{$B C G$ scar present } & \multirow{2}{*}{$\begin{array}{l}B C G \text { scar } \\
\text { absent }\end{array}$} \\
\hline & $\begin{array}{l}\text { Mantoux } \\
\text { l/looo } \\
\text { Positive }\end{array}$ & $\begin{array}{l}\text { Mantoux } \\
\text { l/IO(O) } \\
\text { Negative }\end{array}$ & \\
\hline Total number & 58 & 54 & 37 \\
\hline \multicolumn{4}{|l|}{ Mother (mean (SD)) } \\
\hline Years in England & $5 \cdot 0(5.5)$ & $5 \cdot 8(5 \cdot 7)$ & $5 \cdot 3(4 \cdot 8)$ \\
\hline Previous births & $1 \cdot 0(1 \cdot 1)$ & $1 \cdot 1(1 \cdot 6)$ & $1.7(1.7)^{*}$ \\
\hline Educational class $\ddagger$ & $2.4(1.7)$ & $2 \cdot 6(1 \cdot 7)$ & $1.9(1.7)$ \\
\hline Language ability $\dagger$ & $2 \cdot 6(1 \cdot 3)$ & $2.5(1.3)$ & $2 \cdot 1(1 \cdot 3) \dagger$ \\
\hline \multicolumn{4}{|l|}{ Religion (no $(\%)$ ) } \\
\hline Moslem $(n=91)$ & $31(34)$ & $33(36)$ & $27(30)$ \\
\hline Hindu $(n=23)$ & $10(43)$ & $11(48)$ & $2(9)$ \\
\hline Sikh $(n=35)$ & $17(49)$ & $10(29)$ & $8(22)$ \\
\hline \multicolumn{4}{|l|}{ Father (mean (SD)) } \\
\hline Social class\$ & $3.3(0.9)$ & $3.5(0.8)$ & $3.9(0.9)^{*}$ \\
\hline
\end{tabular}

${ }^{*}$ Result significantly different from that in Mantoux positive group, $\mathrm{P}<0.01$, $\dagger \mathrm{P} \bumpeq(0 \cdot 08$.

$\Varangle$ Higher figure indicates 'better' or 'greater'-see methods.

\$Higher figure indicates 'lower' social class-Registrar General's classification.

Table 3 Nutritional status during pregnancy and at birth in 149 Asian children given $B C G$ vaccination at birth and grouped according to vaccine response at 22 months of age

\begin{tabular}{|c|c|c|c|}
\hline \multirow[t]{2}{*}{ Characteristic } & \multicolumn{2}{|c|}{$B C G$ scar present } & \multirow{2}{*}{$\begin{array}{l}B C G \text { scar } \\
\text { absent }\end{array}$} \\
\hline & $\begin{array}{l}\text { Mantoux } \\
\text { I/1000 } \\
\text { Positive }\end{array}$ & $\begin{array}{l}\text { Mantoux } \\
\text { I/IOOO } \\
\text { Negative }\end{array}$ & \\
\hline Total number & 58 & 54 & 37 \\
\hline \multicolumn{4}{|l|}{$\begin{array}{l}\text { Dietary supplement received by } \\
\text { mother }\end{array}$} \\
\hline Protein, energy, vitamins & 16 & 20 & 11 \\
\hline Energy, vitamins & 24 & 18 & 7 \\
\hline Vitamins $($ no $(\%))$ & $18(31)$ & $16(30)$ & $19(51)^{*}$ \\
\hline \multicolumn{4}{|l|}{ Gestational age (weeks). } \\
\hline Mean (SD) & $39.1(1.4)$ & $38.7(1.9)$ & $39.4(1.1)$ \\
\hline \multicolumn{4}{|l|}{ Weight (kg). } \\
\hline Mean (SD) & $3 \cdot 10(0 \cdot 4)$ & $3 \cdot 07(0 \cdot 5)$ & $3 \cdot 05(0 \cdot 4)$ \\
\hline $\begin{array}{l}\text { Head circumference }(\mathrm{cm}) \text {. } \\
\text { Mean (SD) }\end{array}$ & $34 \cdot 2(1 \cdot 2)$ & $34 \cdot 0(1 \cdot 6)$ & $33.9(1 \cdot 3)$ \\
\hline \multicolumn{4}{|l|}{ Skinfolds $(\mathrm{mm})$. Mean $(\mathrm{SD})$} \\
\hline Triceps & $3.9(1.0)$ & $4 \cdot 0(1 \cdot 1)$ & $3.6(0 \cdot 8) \div$ \\
\hline $\begin{array}{l}\text { Subscapular } \\
\text { Weight for gestational age. }\end{array}$ & $4 \cdot()(1 \cdot 0)$ & $4 \cdot 2(0 \cdot 9)$ & $3 \cdot 6(0 \cdot 8)+$ \\
\hline $\begin{array}{l}\text { sex. parity and maternal } \\
\text { height (SD score) }\end{array}$ & $-0.33(0.9)$ & $-0.21(1 \cdot 0)$ & $-0 \cdot 64(0 \cdot 8) \S$ \\
\hline
\end{tabular}

Only mothers receiving vitamins were regarded as controls in a trial of the effect of dietary protein energy supplements during pregnancy-see methods and references. ${ }^{4} y$

*Proportion greater than in all children with a scar $\mathrm{P}<0.0 .5$

$++\$$ Mean significantly less than in all children with a scar $+\mathrm{P}<0) \cdot(07, \quad+\mathrm{P}<0 \cdot 01$. $\$ \mathrm{P}<0 \cdot(05$.
The latter group had a significantly larger number of siblings, poorer maternal language ability, and lower paternal social class. The group also contained a disproportionately large number of Pakistani children whose mothers had received less education; but these differences did not reach significance.

Nutritional status at birth. Anthropometry at birth was similar in the Mantoux positive and negative groups. The scar absent babies, however, were thinner at birth, lighter for gestational age, and fewer of their mothers had received a protein energy or energy supplement during pregnancy (Table 3).

\section{Discussion}

A quarter of the children who received BCG at birth had no scar and many of those with a scar had neither in vivo nor in vitro evidence of a satisfactory immunological response to tuberculin. Whether these children are protected from tuberculosis is unclear but questions on the policy of giving BCG at birth are raised.

Possibility of artefact. Do the results reflect deficiencies in the administration of the BCG or tuberculin? The BCG was given to all children by one of five senior house officers in paediatrics. Possibly some of the children with no visible scar had been vaccinated unsatisfactorily, however, there was no clumping of absent scars over the one year period to suggest poor technique of one person or a defective batch of vaccine. The 112 children with a scar are assumed to have mounted an initial response to the vaccination, even though later they were Mantoux negative. Purified protein derivative was given by the same person $(\mathrm{HG})$ in all cases and the reading of Mantoux results was standardised (see Methods). Possibly a few negative responses were due to faulty administration but it is unlikely that all negative results were caused by this, and many of the Mantoux negative children also had in vitro evidence of a diminished response (their lymphocyte transformation response to purified protein derivative was less than $50 \%$ of the control value in two thirds of children). It seems unlikely, therefore, that the results are due to technical errors. It seems more probable that they reflect the physiological situation.

Physiological implications. Impaired reaction to tuberculin in a previously vaccinated person may be caused by a defect of initial recognition of the antigen or ability to retain this information (for 
example, the immunological immaturity of preterm infants) ${ }^{1.3}$ or, more commonly, it may be due to failure of sensitised lymophocytes to react because the individual is malnourished or has a serious infection. ${ }^{14}$

There was some evidence of impaired reactivity of lymphocytes since the reaction to non-specific mitogens was often below that of controls. The psychomotor development of the Mantoux negative and scar absent groups was a little behind, and the Mantoux negative group were a little lighter, shorter, and thinner-we regard these features as evidence of their less privileged background. No child, however, was clinically ill or overtly malnourished and none had evidence of severe deficiencies of protein, energy, iron, or zinc. It seems unlikely that these minor differences at the age of 22 months could account for the substantial reduction (cf controls) in the in vitro reaction to purified protein derivative and the substantial number of Mantoux negative children.

There is circumstantial evidence, however, to question the initial acquisition of immunity to BCG in the neonatal period and also immunological memory. A quarter of the children receiving BCG failed to react sufficiently to produce a scar, that is, a perinatal phenomenon operative at the time of vaccination. It may be that many of the Mantoux negative responses in children with a scar are also due to a phenomenon at the time of vaccination rather than a defect at the time of Mantoux testing.

The nature of this perinatal phenomenon is unclear. It is possible that it represents a stage of normal development (for example, immunological 'immaturity'). BCG at birth, however, achieved Mantoux conversion in a high proportion of neonates in Chicago. ${ }^{2}$ Possibly our Asian babies have genetically induced differences in the immunological status at birth-it would be useful to repeat this study in a group of European children but very few of these receive BCG at birth. Indirect evidence against a genetic explanation comes from a study of contact tracing (although admittedly in adults). While $3.9 \%$ of unvaccinated Asian contacts developed tuberculosis compared with $1 \cdot 6 \%$ of a vaccinated group, the results in non-Asians were $4.4 \%$ and $1.1 \%$ respectively; that is, there was a similar degree of protection in the different races. ${ }^{15}$

Could there have been environmental interference with the initial 'take' of the vaccine? Infection with atypical mycobacteria are cited as a possible reason for the poor protection against tuberculosis by $\mathrm{BCG}$ in India, ${ }^{16}$ and it is possible that maternal antibodies against such mycobacteria may have had an effect on the initiation of immunity in the neonate. Unfortunately, we have no record of maternal antibodies at the time of birth of children in this study.

Others ${ }^{13}{ }^{17}$ have shown impaired cell mediated immunity at birth in small for gestational age babies and found that this may remain abnormal for at least 12 months. This could explain some of the results, in that the scar absent group was lighter for gestational age at birth (see Table 3 ) than those who reacted with a scar, and fewer of their mothers had received a protein energy supplement during pregnancy.

Implications for immunisation programmes. Tuberculosis in Asian children in Britain is still a problem. The notification rates in 1978-9 per 100000 for Indian and Pakistani children born in the United Kingdom were 72 , and 95 respectively, compared with only 3.6 for white children. ${ }^{18}$

BCG vaccination, if it is effective, is desirable therefore in early life, particularly in view of the higher risk of dissemination in this age group, and vaccination shortly after birth before discharge from hospital is administratively simple. While the failure to produce a scar or to react to a Mantoux test does not necessarily imply susceptibility to tuberculosis the results of this study show that further evaluation is necessary. We suspect that only a controlled prospective trial (for example, comparing the incidence of tuberculosis in those vaccinated at birth, vaccinated at 3 months, and not vaccinated) will provide the answer but in view of the low incidence of tuberculosis, even in Asians, a large number of subjects would be required. An alternative may be the case control method. ${ }^{19}$

Despite the contradictory results of BCG vaccination (see introduction) it is compulsory in 64 countries and recommended in 118 others. ${ }^{20}$ Recently, the World Health Organisation Expanded Programme of Immunisation recommended BCG at 3 months $^{7}$ (previously birth to 1 month) and in many areas there is vaccination at school entry and in adolescence. Determination of the optimum time for the first BCG vaccination requires further study.

Dr S Bakshi, Specialist in Community Medicine, with particular responsibility for the immunisation programme in Birmingham. advised on many aspects of the study. Health visitors Mrs Gregory, Mrs Howell, Mrs Humphries, and Mrs Scott helped in the assessment of the children, Dr E Ball provided hacmatological data, the medical illustration department, Birmingham Children's Hospital provided the figures. We thank all of them and Mrs Peggy Cox for secretarial assistance.

\section{References}

1 Ferguson RG, Simes AB. BCG vaccination of Indian infants in Saskatchewan. Tubercle 1949;30:5-11.

2 Rosenthal SR, Loewinsohn E, Graham ML, Liveright D, Thorne MG, Johnson $\mathrm{V}$. BCG vaccination against tuberculosis in Chicago. A twenty year study statistically analysed. Pediatrics $1961 ; 28: 622-41$ 
${ }^{3}$ Anonymous. BCG vaccination in the newborn (editorial). $\mathrm{Br}$ Med J 1980:ii: 1445-6.

+ Hart PDA, Sutherland I. BCG and vole bacillus vaccines in the prevention of tuberculosis in adolescence and early adult life. $\mathrm{Br}$ Med J 1977;ii:293-5.

s Comstock GW. Palmer CE. Long term results of BCG vaccination in the southern United States. Am Rev Respir Dis 1966:93:171-83.

6 Tuberculosis prevention trial. Trial of BCG vaccines in south India for tuberculosis prevention. Bull WHO 1979;57:819-27.

7 Ten Dam HG, Hitze KI. Does BCG vaccination protect the newborn and young infants? Bull WHO 1980;58:37-41.

* Vicgas OAC, Scott PH, Cole TJ, Mansficld HN, Wharton P, Wharton BA. Dietary protein energy supplementation of pregnant Asian mothers at Sorrento, Birminghan. I: unselective during second and third trimesters. Br Med J 1982:285: $589-92$.

"Viegas OAC, Scott PH, Cole TJ, Eaton P. Needham PG, Wharton BA. Dictary protein energy supplementation of pregnant Asian mothers at Sorrento, Birmingham. II: selectivc during third trimester only. $\mathrm{Br}$ Med J 1982;285:592-5.

11) National Centre for Health Statistics. NCHS growth charts. Vital and health statistics. Series 11. Rockville: US Government Printing Office. 1976.

$"$ Caplin M. The tuberculin test in clinical practice. London: Bailliere Tindall, 1980:10-21.

12 Ling NR, MacLennon ICM. Analysis of lymphocytes in blood and tissues. In: Thompson RA, ed. Techniques in clinical immunology. London: Blackwell, 1982:222-54.
1.3 Chandra RK. Serum thymic hormone activity and cell mediated immunity in healthy neonates, preterm infants and small for gestational age infants. Pediatrics 1981;67:407-11.

it Chandra RK. Interactions of nutrition. infection and immune response. Acta Paediatr Scand 1979;68:137-44.

15 Contact Study Sub-committec of the British Thoracic Association. A study of a standardised contact procedure in tuberculosis. Tubercle 1978:59:245-59.

16 Stanford JL. Shield MJ, Rook GAW. How environmental mycobacteria may predetermine the protective efficacy of BCG. Tubercle 1981:62:55-62.

${ }^{17}$ Ferguson AC. Prolonged impairment of cellular immunity in children with intrauterine growth retardation. $J$ Pediatr 1978;93:52-6.

${ }^{18}$ Medical Research Council Tuberculosis and Chest Diseases Unit. Tuberculosis in children in a national survey of notifications in England and Wales. 1978-79. Arch Dis Child 1982:57:734-41.

${ }^{19}$ Smith PG. Retrospective assessment of the effectiveness of BCG vaccination against tuberculosis using a case/control method. Tubercle 1982;63:1-23.

20) Anonymous. Is BCG vaccination effective? (editorial). Tubercle 1981:62:219.

Correspondence to Dr H Grindulis. Sorrento Maternity Hospital. Wake Green Road, Moseley. Birmingham.

Received 22 March 1984 